\title{
Failure Evolution Law of Reinforced Anchor System under Pullout Load Based on DIC
}

\author{
Yue Li $\left(\mathbb{D},{ }^{1}\right.$ Chongming Gao $\mathbb{D D}^{1}{ }^{1}$ Qian Li $\mathbb{D},{ }^{2}$ Qiqi Wu, ${ }^{1}$ and Wenjun Meng ${ }^{1}$ \\ ${ }^{1}$ School of Civil Engineering, North China University of Technology, Beijing 100144, China \\ ${ }^{2}$ Research Institute of Highway Ministry of Transport, Beijing 100088, China \\ Correspondence should be addressed to Qian Li; qian.li@rioh.cn
}

Received 3 November 2020; Revised 1 December 2020; Accepted 14 December 2020; Published 29 December 2020

Academic Editor: Zhigang Zhang

Copyright (C) 2020 Yue Li et al. This is an open access article distributed under the Creative Commons Attribution License, which permits unrestricted use, distribution, and reproduction in any medium, provided the original work is properly cited.

To obtain the failure evolution law, a pullout test model of the anchor system is proposed based on the digital image correlation (DIC) measurements. By the study of the displacement field, the strain field, and the force transfer law of the anchor system under the pulling load, the failure law of the anchor system is revealed. The results show that (1) the failure mode and the ultimate bearing capacity of the anchor system are related to the thickness of the anchor agent; (2) in the anchor system, the pulling force is gradually transferred from the loading end to the free end along the steel bar, and the greater the thickness of the anchoring agent, the deeper the transfer range; (3) during the loading, the deformation of the anchoring system is mainly concentrated at the interface between the anchoring agent and the concrete and expands to the depth along the steel bar; and (4) the failure evolution rate of the anchorage system is related to the loading stage. The failure evolution of the anchor system can be divided into the elastic phase, the plastic phase, and the deformation rebound phase.

\section{Introduction}

The need to reduce on-site construction time in civil infrastructure has led to an important increase in the use of precast concrete elements (PCEs). PCEs provide structures with higher material quality, better durability, reduced environmental impact, and increased work zone safety. The connection of these elements is typically done using fieldcast nonshrink cementitious grouts [1-4]. The grout material not only needs to exhibit enough strength, but it should also offer a good bond to the concrete element to ensure adequate stress transfer.

Bond in cementitious materials is a topic that has been extensively researched in the past decades [5-10].

Studies of grout interface for rebar show that bonding forces is made up of three components: chemical adhesion, friction, and mechanical interlock. The adhesive strength between the interface is negligible $[11,12]$. In addition, the adhesive strength of the bond cannot be mobilised with frictional strength during the pullout process [13]. The frictional components can be categorized into dilation slip, shear failure of surrounding medium, and torsional resistance of rebar [14]. The mechanical interlock component of the bond strength plays an important role in the load transfer capacity of the reinforced anchor system [15].

However, despite a relatively large body of knowledge, there is still a lack of a good understanding of the failure evolution law, which has prevented the development of rational anchorage design procedures. This is due mainly to the fact that all kinds of transducer embedded in concrete can only be used to monitor the particular deformation at a certain region and it is difficult to directly observe the internal failure process of the anchor system. If the damage and crack arose at the other region that has not been monitored by an embedded transducer, it would fail to get any valuable data. However, the deformation in these regions is important because it might cause the entire failure eventually. It is difficult to determine the possible weak regions for concrete by theoretical analysis and calculation beforehand due to many holes and microcracks exist in concrete. Sometimes concrete might break in the region that was considered as low stress previously because damage in 
this region would result in the redistribution of stress [16-18].

The full-field measurement method provides a solution to the above problems which is more adapted than pointbased techniques to provide 2D displacement and strain field within a given zone in the specimen. Among others, Digital Image Correlation (DIC) is probably the most widely adopted noncontact measuring technique in the material testing and structure monitoring domain. DIC is an optical technique to detect and quantify changes between a series of digital images. DIC-based approaches are used as noncontact measurement techniques to analyze $2 \mathrm{D}$ and 3D displacement fields. The early development of these techniques in the mechanics' research domain dates to the 80s [19-21]. Recent technological advances in high-resolution digital cameras have considerably increased the popularity of these methods and widened their application to different civil engineering problems [22]. DIC has been successfully applied for displacements measurement and crack monitoring of different materials and structural systems. Based on DIC, Muller et al. [23] analyzed the strengthening of RC specimens with composite plates, Tung et al. [24] studied crack variations in masonry walls, and Ghiassi et al. [25] investigated the evolution of strain fields in uniaxial tensile and shear debonding tests carried out on FRP reinforced masonry systems. Helm [26] used DIC to identify multiple growing cracks on an RC slab. Choi and Shah [27] analyzed the nonuniform displacements to detect the microscopic fracture process at the interface between the cement matrix and the aggregate by DIC.

Therefore, based on the advantages of DIC, it is realized a comprehensive observation and investigation of the failure evolution law of the anchorage system during the loading process. In this paper, based on DIC measurements, a pullout test model of the anchor system is proposed. Through the pullout test, the loading transmission route of the reinforcing bar, the displacement field, and the strain field of the anchor system can be observed during the whole loading process. The deformation evolution characteristics of the interface in the anchor system are analyzed and the fail evolution law is explored.

\section{Digital Image Correlation Principles}

DIC method is mainly used to measure the deformation field of a material or structure surface under external load or other factors. It has the advantages of full-field measurement, noncontact, relatively simple optical path, and adjustable measurement horizon. Ruocci et al. [28] pointed out that it was a measurement technique that could provide the full-field surface displacement in the region of interest by using a series of digital images taken at different loading steps as input. In the application of DIC, speckles on a specimen surface before and after deformation are digitized into source and target images. As illustrated in Figure 1(a), the image is divided into a grid of subsets (i.e., a square group of pixels), which is identified by a distinctive grey value pattern. If it assumes that the grey value distribution of the same subset in both images remains unchanged to deformation, the subsets matching can be performed by maximizing the correlation between their greyscale values. In Figure 1, points $P\left(x_{P}, y_{P}\right)$ and $Q\left(x_{Q}, y_{Q}\right)$ in the source image move to $P^{*}$ and $Q^{*}$ in the target image. Equation (1) is used to express the relationship between these two points:

$$
\begin{aligned}
& x_{Q}=x_{P}+\Delta_{x}, \\
& y_{Q}=y_{P}+\Delta_{y},
\end{aligned}
$$

where $\Delta x$ and $\Delta y$ are the distances between points $P$ and $Q$ along $x$ and $y$ directions. After deformation, displacements of point $P$ are $u_{P}$ and $v_{P}$, and point $Q$ are $u_{Q}$ and $v_{Q}$ in the $x$ and $y$ directions, respectively:

$$
\begin{aligned}
& x_{P}^{*}=x_{P}+u_{P}, \\
& y_{P}^{*}=y_{P}+v_{P}, \\
& x_{Q}^{*}=x_{Q}+u_{Q}, \\
& y_{Q}^{*}=y_{Q}+v_{Q} .
\end{aligned}
$$

Considering tensile and shear effects with very small $\Delta x$ and $\Delta y, u_{Q}$ and $v_{Q}$ are represented as [29]

$$
\begin{gathered}
u_{Q}=u_{P}+\frac{\partial_{u P}}{\partial_{x}} \Delta_{x}+\frac{\partial_{u P}}{\partial_{y}} \Delta_{y}, \\
v_{Q}=v_{P}+\frac{\partial_{v P}}{\partial_{x}} \Delta_{x}+\frac{\partial_{v P}}{\partial_{y}} \Delta_{y} .
\end{gathered}
$$

Substituting equations (1) and (3) into (2), then

$$
\begin{aligned}
& x_{Q}^{*}=x_{P}+u_{P}+\frac{\partial_{u P}}{\partial_{x}} \Delta_{x}+\frac{\partial_{u P}}{\partial_{y}} \Delta_{y}, \\
& y_{Q}^{*}=y_{P}+v_{P}+\frac{\partial_{v P}}{\partial_{x}} \Delta_{x}+\frac{\partial_{v P}}{\partial_{y}} \Delta_{y} .
\end{aligned}
$$

Generally, for an arbitrary point $Q$,

$$
\begin{aligned}
& x^{*}=x+u+\frac{\partial_{u}}{\partial_{x}} \Delta_{x}+\frac{\partial_{u}}{\partial_{y}} \Delta_{y}, \\
& y^{*}=y+v+\frac{\partial_{v}}{\partial_{x}} \Delta_{x}+\frac{\partial_{v}}{\partial_{y}} \Delta_{y} .
\end{aligned}
$$

In the case of a very small $P Q$, the following relationships can be obtained: 


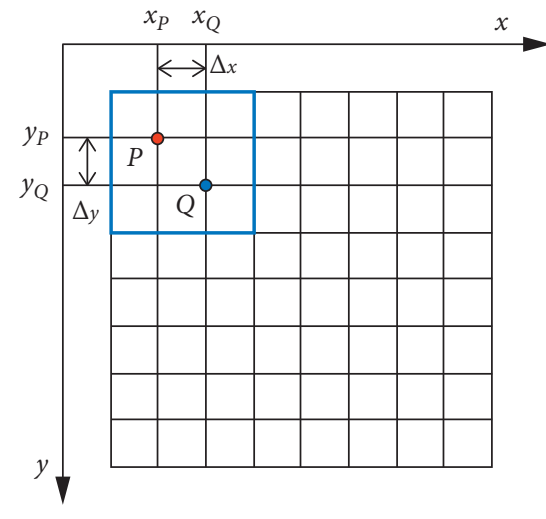

(a)

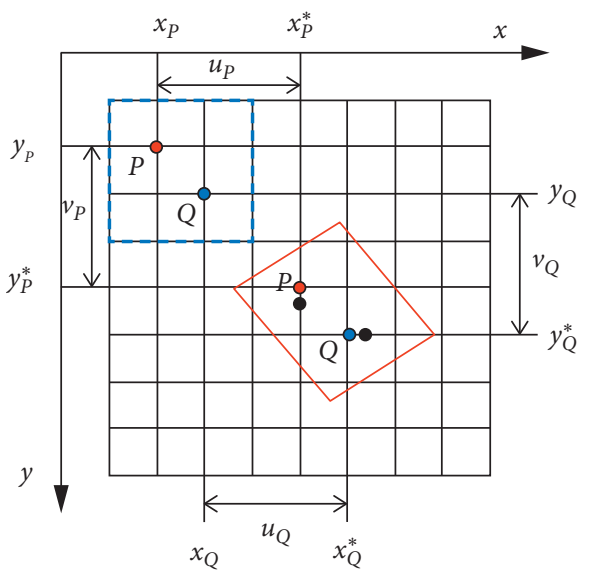

(b)

FIGURE 1: Illustrative of the principle of DIC in-plane displacements. (a) Before deformation $f(x, y)$. (b) After deformation $g\left(x^{*}, y^{*}\right)$.

$$
\begin{aligned}
& d_{x}=x_{Q}-x_{P}, \\
& d_{y}=y_{Q}-y_{P}, \\
& d_{x}^{*}=x_{Q}^{*}-x_{P}^{*}, \\
& d_{y}^{*}=y_{Q}^{*}-y_{P}^{*} .
\end{aligned}
$$

The distance before and after deformation can be obtained as follows:

$$
\begin{gathered}
|P Q|^{2}=(d x)^{2}+(d y)^{2}, \\
\left|P^{*} Q^{*}\right|^{2}=\left(d x^{*}\right)^{2}+\left(d y^{*}\right)^{2} .
\end{gathered}
$$

Therefore, the strain in all direction can be defined as

$$
\begin{aligned}
& \varepsilon_{x x}=\frac{\partial_{u}}{\partial_{x}}+\frac{1}{2}\left[\left(\frac{\partial_{u}}{\partial_{x}}\right)^{2}+\left(\frac{\partial_{v}}{\partial_{x}}\right)^{2}\right], \\
& \varepsilon_{y y}=\frac{\partial_{v}}{\partial_{x}}+\frac{1}{2}\left[\left(\frac{\partial_{u}}{\partial_{y}}\right)^{2}+\left(\frac{\partial_{v}}{\partial_{y}}\right)^{2}\right], \\
& \varepsilon_{x y}=\frac{1}{2}\left(\frac{\partial_{u}}{\partial_{y}}+\frac{\partial_{v}}{\partial_{x}}\right)+\frac{1}{2}\left[\frac{\partial_{u}}{\partial_{x}} \frac{\partial_{u}}{\partial_{y}}+\frac{\partial_{v}}{\partial_{x}} \frac{\partial_{v}}{\partial_{y}}\right] .
\end{aligned}
$$

Figure 1 shows the in-plane displacement field $(u, v)$ which is determined by matching subsets $S$ and the corresponding subset $S^{*}$ before and after the deformation [30,31]. The typical correlation function is expressed by

$$
C=\frac{\sum_{i}^{M}=-M \sum_{j}^{m}=-M\left[f\left(x_{i}, y_{i}\right)-\bar{f}\right]\left[g\left(x_{i}^{\prime}, y_{i}^{\prime}\right)-\bar{g}\right]}{\sqrt{\sum_{i}^{M}=-M \sum_{j}^{m}=-M\left[f\left(x_{i}, y_{i}\right)-\bar{f}\right]^{2} \sqrt{\sum_{i}^{M}=-M \sum_{j}^{m}=-M\left[g\left(x_{i}^{\prime}, y_{i}^{\prime}\right)-\bar{g}\right]^{2}}}}
$$

where $C$ is the correlation coefficient, $f\left(x_{i}, y_{i}\right)$ and $g\left(x_{i}^{\prime}, y_{i}^{\prime}\right)$ are the grey values of points in subsets before and after deformation, and $\bar{f}$ and $\bar{g}$ are the average grey values of $f\left(x_{i}, y_{i}\right)$ and $g\left(x_{i}^{\prime}, y_{i}^{\prime}\right)$.

\section{Experimental Program}

3.1. Pullout Test Model of the Anchor System. Figure 2 shows the specimen model in the conventional pullout test which is always a concrete cylinder. The rebar generally deforms in the axial direction but not out of plane due to the restraint by the surrounding material. The load, constraint, and geometric model are all axial symmetry; therefore, the stress and strain of the reinforcing bars and concrete are axisymmetrically distributed during the loading process. From the Kelvin problem in the elastic mechanics, the concentrated force produces symmetrical strain and displacement to the axis of the rebar which has no concern with the hoop coordinate. Therefore, the model is designed as shown in Figure 3 in order to observe the displacement field on the interfaces of the bar-grout agent-concrete and investigate the failure evolution law of the anchorage system. The model consisted of a concrete semicylinder in which a $\phi 25 \mathrm{~mm}$ hot-rolled ribbed rebar was anchored at the center of the axial surface. Based on Chinese Code for Design of Concrete Structures (GB50010-2010) [32], the anchorage length of the rebar should be at least $600 \mathrm{~mm}$, so the height of the specimen is designed as $700 \mathrm{~mm}$. At the same time, the diameter of the semicylinder specimen is $350 \mathrm{~mm}$ which is 14 times the diameter of the rebar for reducing the influence of the concrete body size and effectively observing the evolution of the displacement field of the rebar-grouting agent-concrete. The observing surface was painted in black and sprayed with white spots to form the artificial speckle 


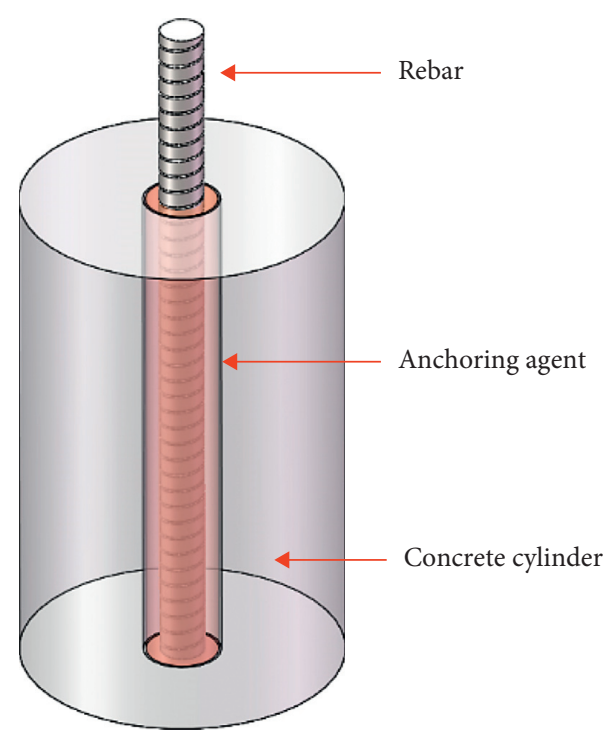

FIgURE 2: Conventional model in the pullout test.

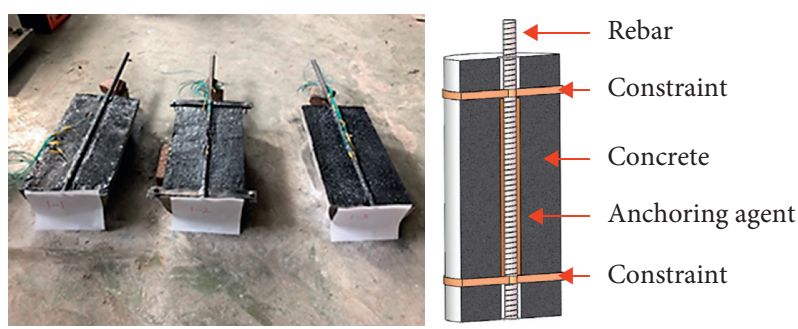

FIGURE 3: Proposed model in the pullout test.

field. Two steel ring hoops with $20 \mathrm{~mm}$ wide and $5 \mathrm{~mm}$ thick were set on the top and bottom as the constraint to prevent the out of plane displacement of the rebar.

Many factors affect the bonding performance between two materials, the anchoring agent thickness being one of them. The bars are anchored in holes with diameters of 40, 50,75 , and $160 \mathrm{~mm}$ corresponding to the anchoring agent thickness of 8, 13, 25, and $93 \mathrm{~mm}$, respectively. The details of the specimen parameters are shown in Table 1.

3.2. Specimen Manufacture. An ordinary Portland cement $\mathrm{P} . \mathrm{O} 42.5$ with a Blaine fineness of $382 \mathrm{~m}^{2} / \mathrm{kg}$ and a density of $3070 \mathrm{~kg} / \mathrm{m}^{3}$ was used to prepare the concrete. The fine aggregate (FA) was an ordinary river sand with an apparent specific gravity of 2.59 . The coarse aggregate (CA) consisted of dolomitic limestone with an apparent specific gravity of 2.85. The concrete mixture was developed to perform similarly to a prefabricated concrete element in terms of strength. Therefore, the concrete was designed with a waterto-cement ratio of 0.35 by mass, cement : FA : CA ratio of 1 : $1.7: 2.5$ (by mass), and a targeted $28 \mathrm{~d}$ compressive strength of $55 \mathrm{MPa}$.

The available commercially nonshrink cementitious grout was used in the test. The grout was supplied in a bag containing the solid fraction that was mixed with a certain amount of water following the manufacture's recommendations. The grout had a water-to-solid ratio of 0.16 by mass and produces a $28 \mathrm{~d}$ compressive strength of $62 \mathrm{MPa}$.

The specimen manufacture process includes 4 steps. First, corresponding to the specimens, the PVC pipes with different diameters were embedded in the mold as the reserved holes. Then, the concrete was vibrated in the mold, as shown in Figure 4(a). Second, after 24 hours of concrete solidification and formation, the mold and PVC pipe were removed, as shown in Figure 4(b). Third, the specimens were cured for 28 days. After that, the anchoring agent was put into the reserved hole. The reinforcing bar attached with strain gauge was put in the anchoring agent and kept half of the bar without the strain gauge being covered by the anchoring agent, as shown in Figure 4(c). Last, after 24 hours, the top of the specimen as the target surface was smoothed and painted to black background. Then, the white spots were sprayed on the surface to make artificial speckle field, as shown in Figure 4(d).

3.3. Test Procedure and Observation System. The test system including an XY-350 hydraulic pullout instrument and a reaction rack was used to apply load at the specimen (as illustrated in Figure 5). The XY-350 hydraulic puller was put on the top plate of the reaction rack, and the specimen was placed under the plate to ensure the specimen was in axial tension state as much as possible. 
TABLE 1: Specimen parameters.

\begin{tabular}{lccc}
\hline Number & Rebar diameter $(\mathrm{mm})$ & Hole diameter $(\mathrm{mm})$ & Anchoring agent thickness $(\mathrm{mm})$ \\
\hline SJ-40 & 25 & 40 & 8 \\
SJ-50 & 25 & 50 & 13 \\
SJ-75 & 25 & 75 & 25 \\
SJ-160 & 25 & 160 & 93 \\
\hline
\end{tabular}

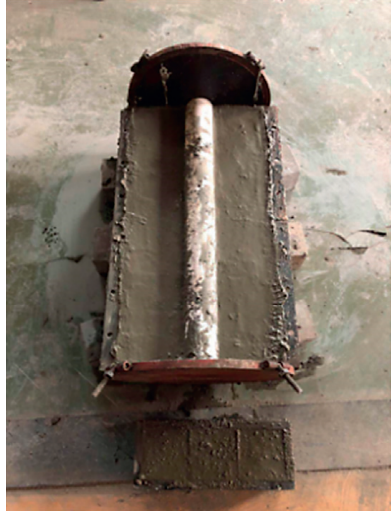

(a)

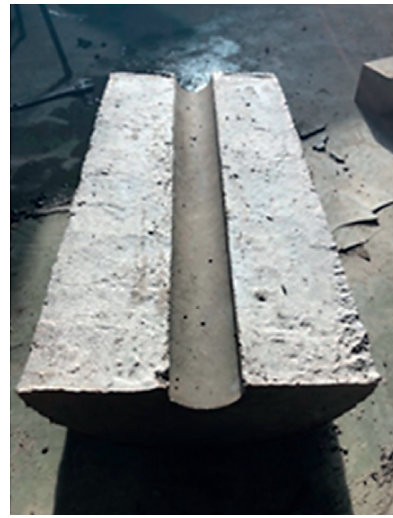

(b)

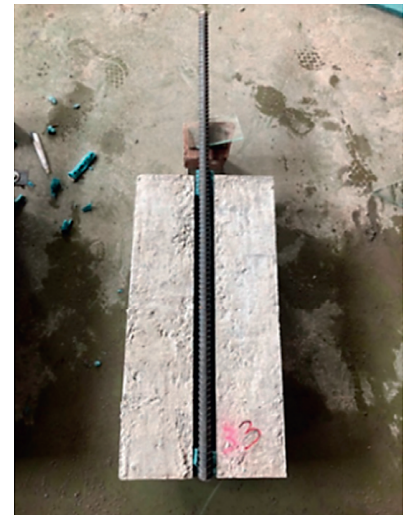

(c)

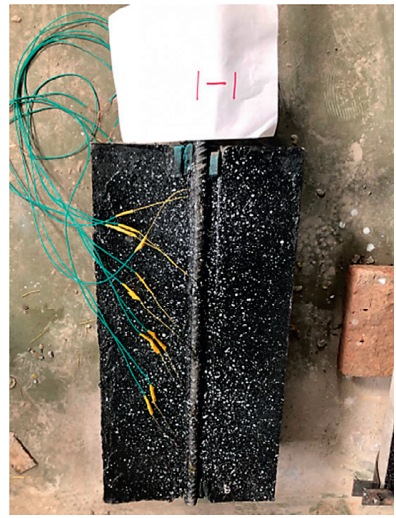

(d)

Figure 4: Specimen manufacture process. (a) Casting concrete matrix. (b) Removing the mold. (c) Embedding the rebar. (d) Spraying speckle.

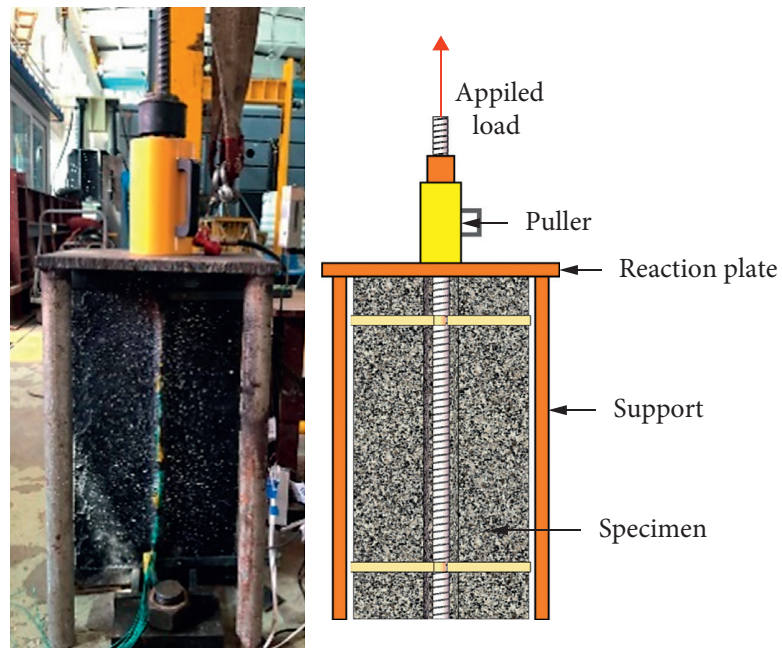

FIGURE 5: Loading system in the test.

In the test, the foil-type resistance strain gauge and one CCD industrial camera were used to collect the deformation data of the reinforcing bar and the target surface, respectively. The strain gauges were placed at 5 measuring points $\left(\mathrm{MP} 1^{\#}-5^{\#}\right)$ from the loading end to the free end along the upper edge of the reinforcement. Due to the symmetry, only left half surface is analyzed. The resolution of the collected speckle image was 1600 pixels $\times 1200$ pixels, and the object surface resolution was $0.24 \mathrm{~mm} /$ pixel. The location of the strain gauge, coordinated system, and analyzed area is shown in Figure 6.

\section{Analysis and Discussion of the Results}

4.1. Failure Modes. The specimens mainly exhibited two failure modes including splitting failure (tensile cracks in the concrete parallel to the reinforcing bar), shown in Figure $7(a)$, and a failure at the interface between the grout and the concrete, shown in Figure $7(\mathrm{~b})$. These failure modes often occurred in conjunction with the formation of a shallow angle concrete cone surrounding the reinforcing bar on the face of the specimen, shown in Figure 7. 


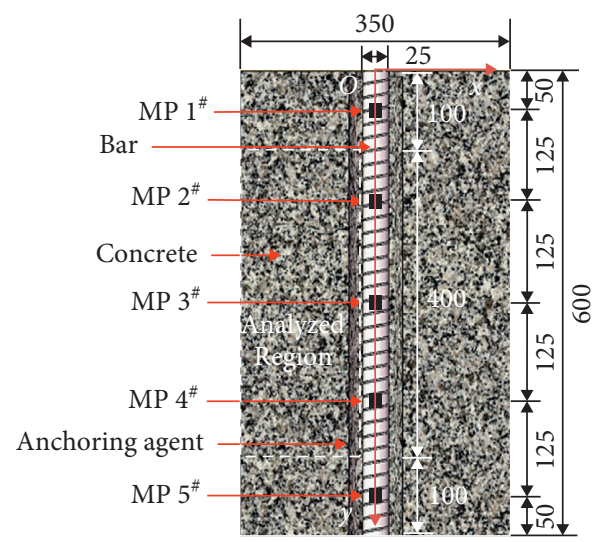

FIgURE 6: Analyzed region and strain gauge position.
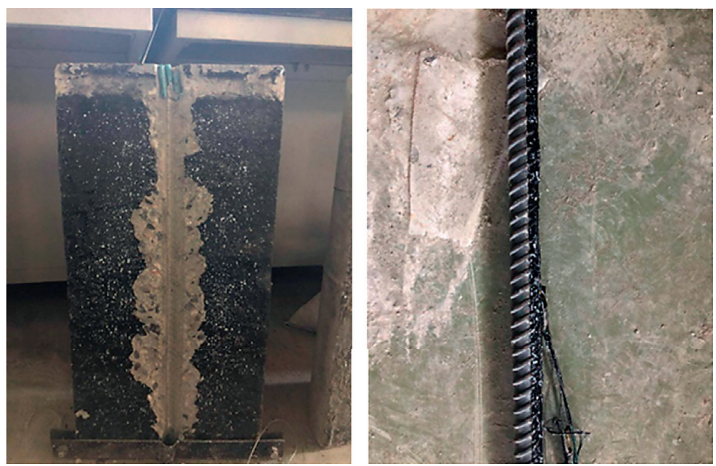

(a)
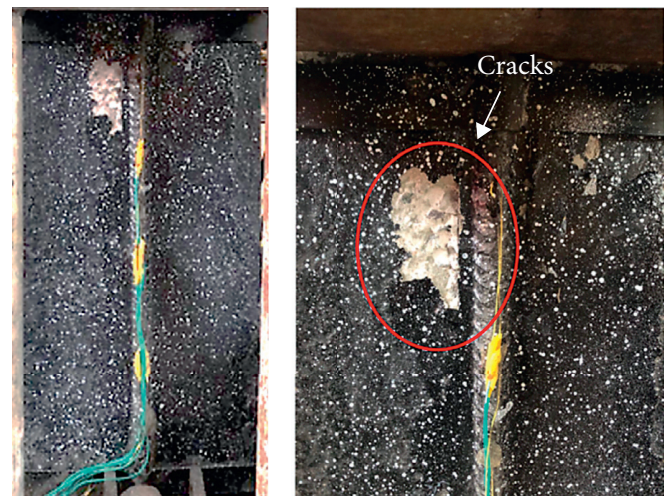

(c)
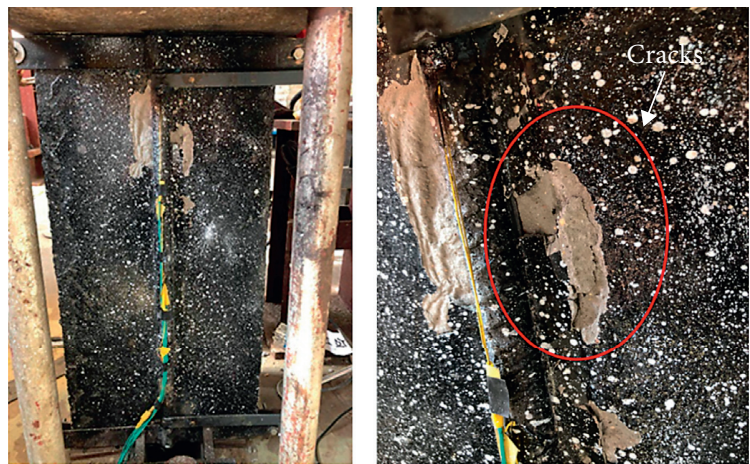

(b)
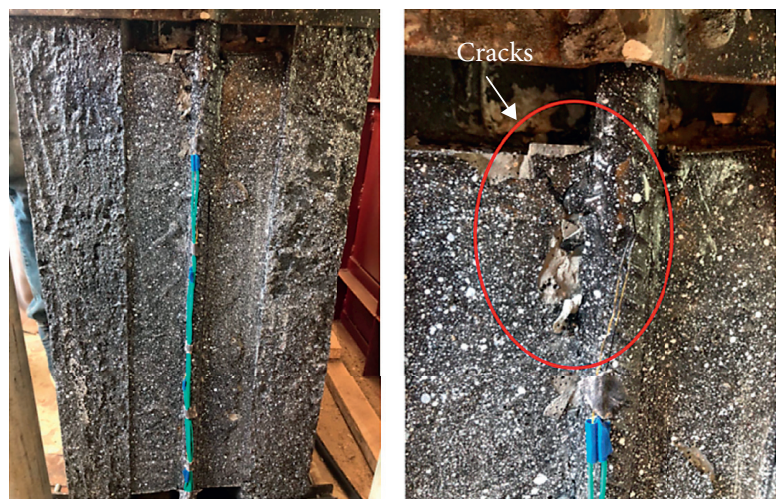

(d)

FIgURE 7: Specimen failure. (a) SJ-40. (b) SJ-50. (c) SJ-75. (d) SJ-160.

For SJ-40, now that there was not sufficient bond strength between the bar and the concrete due to the thin thickness of the grouting agent, it was mainly splitting failure. As the load increases, tensile cracks first appeared at the interface between the bar and the grout near the loading end and developed to the free end. Finally, the cracks penetrated the entire specimen. The bar and the grout were completely debonded, and the specimen was destroyed (as shown in Figure $7(\mathrm{a})$ ). A splitting failure indicates close interaction between the grout and the surrounding concrete and is usually accompanied by the failure at the reinforcing bar-grout interface, not the grout-concrete interface.

With the increase of the grout thickness, the failure modes of SJ-50 and SJ-75 gradually transformed into the cracking at the interface between the grout and the concrete, until to form the shallow angle concrete cone in SJ-160, as shown in Figure 7(d). Failure at the interface between the grout and the concrete indicates a low bond strength between the two materials. The thickness of the grouting agent has a great influence on the failure mode of the anchor system. 
Table 2 shows the ultimate anchoring capacity of the specimen when failure occurs. It can be found that for the reinforced grout anchor connection, the ultimate anchoring capacity increases with the thickness of the grouting agent.

\subsection{Deformation Evolution and Load Transmission Law of the} Bar. Due to the similar law in specimens, SJ-160 is taken as the typical representative for analysis. Figure 8 shows the strain evolution law of the bar. It illustrates that the forcestrain curves present linear increase and the strain at MP $4^{\#}$ and MP $5^{\#}$ are approximately zero before the pullout force is less than $55 \mathrm{kN}$. When the force reaches $55 \mathrm{kN}$, the turning points appear in the force-strain curves of MP $1^{\#}$ to MP $3^{\#}$ and the load has been transmitted to MP $4^{\#}$. The overall deformation of the anchor system is intensified. After that, the strains increase rapidly and the growth rate of MP $1^{\#}>\mathrm{MP} 2^{\#}>\mathrm{MP} 3^{\#}>\mathrm{MP} 4^{\#}$. When the force reaches $62 \mathrm{kN}$, the force-strain curves of MP $1^{\#}-4^{\#}$ turn again. The overall deformation is intensified further.

From the above analysis, it can be found that the pullout force is transmitted from the loading end to the free end along the axial direction of the bar and the strain decreases with the increase of the distance to the loading point. At the same time, the evolution trend of the force-strain curves is similar.

Figure 9 shows the difference of the axial force between the two adjacent measuring points on the bar with the pullout force. At the initial stage, the interface in the anchoring system is in the elastic occlusal deformation stage. In the bar, the force is relatively uniform and the strain at different positions is almost the same. The axial force difference between two adjacent measuring points increases with the pulling force. With the loading increases, the bonding strength becomes weaken, and the growth rate of the strain increases. The interface of the anchorage system near the loading end first enters the plastic deformation. Due to the thread of the reinforcing bar and the load transmitted to the further end, the growth rate of the strain increases again when the load reaches a certain value. When the ultimate bonding strength is reached, the relative slip occurs at the interface, and the static friction is changed to the dynamic friction.

\subsection{Evolution Law of the Deformation Field at the Interface.} Based on the DIC technology, the deformation field map of the analyzed region is given including the displacement field and the strain field.

4.3.1. Evolution Law of the Displacement Field. The displacement field is calculated from equation (1) to equation (7). Taking SJ-160 as an example, Figure 10 shows the horizontal displacement field of the analyzed region. The vertical line marks the interface of the grouting agent and concrete. The zero of the abscissa locates the interface of the bar and the grouting agent and the pixel movement along the $X$-axis direction is specified as positive in the analysis. Both the grouting agent and the concrete tend to movement away from the bar, and the displacement is decreased from the loading end to the free end. As the load increased, the horizontal displacement is also growing. However, due to the material discontinuity at the interface between the grouting agent and the concrete, the contour lines at the interface tend to fluctuate and gradually be transferred from the loading end to the free end with the loading increased. When the loading reaches $96 \mathrm{kN}$, the fluctuation is completely transferred to the free end. The horizontal displacement at the interface of the grouting agent and the concrete is greater than that at the same height.

Figure 11 shows the vertical displacement field of SJ-160. It is specified that the pixel downward movement along the $Y$-axis is as positive in the analysis. During the loading, the vertical displacement fields are all negative. As closer to the bar, the displacement is greater. When the loading reaches $62 \mathrm{kN}$, an outstanding increase district appears at the depth of $50 \mathrm{~mm}$, and the region is expanding. When the loading reaches $96 \mathrm{kN}$, the contour lines have a break at the interface of the grouting agent and the concrete. In the concrete side, the contour lines are basically horizontal. In the grouting agent side, the displacement is larger at the same height as closer to the bar. Moreover, at the distance of $25 \mathrm{~mm}$ from the bar, the displacement is more prominent near the loading end.

4.3.2. Evolution Law of the Strain Field at the Interface. Based on the displacement field, the principal strain is calculated by

$$
\varepsilon_{1,2}=\frac{\varepsilon_{x}+\varepsilon_{y}}{2} \pm \sqrt{\left(\frac{\varepsilon_{x}-\varepsilon_{y}}{2}\right)^{2}+\left(\frac{\gamma_{x y}}{2}\right)^{2}} .
$$

Taken SJ-160 as an example, the $\varepsilon_{1}$ field is shown in Figure 12. At the beginning of loading, $\varepsilon_{1}$ is mainly concentrated near the loading end in the grouting area.

When the loading reached $75 \mathrm{kN}$, the influence range of $\varepsilon_{1}$ has been transmitted to the free end along $Y$-axis. At the ultimate strength $96 \mathrm{kN}, \varepsilon_{1}$ at the interface between the concrete and the grouting agent gradually expands to the both sides. At last, $\varepsilon_{1}$ is developed to the bar, and the specimen failed.

Based on the principal strain field, the maximum shear strain can be further calculated by

$$
\gamma=\frac{\varepsilon_{1}+\varepsilon_{2}}{2}
$$

where $\gamma$ is the maximum shear strain, $\varepsilon_{1}$ is the first principal strain, and $\varepsilon_{2}$ is the second principal strain.

The $\gamma$ field is illustrated in Figure 13. At the initial stage, $\gamma$ mainly exists in the grouting agent near the bar at the loading end. Then, the range of $\gamma$ is extended to concrete region along the $Y$-axis. When the loading reaches $96 \mathrm{kN}$, the $\gamma$ at the interface of the bar and grouting agent is much more than the other region. And the shallow angle concrete cone is pulled out from the specimen.

As shown in Figure 13(a), in the initial stage of loading corresponding to the drawing force $36 \mathrm{kN}, \gamma$ is mainly 
TABle 2: Pulling force when the specimen is broken.

\begin{tabular}{lccc}
\hline Number & Rebar diameter $(\mathrm{mm})$ & Anchoring agent thickness $(\mathrm{mm})$ & Ultimate anchoring capacity $(\mathrm{kN})$ \\
\hline SJ-40 & 25 & 8 & 49.00 \\
SJ-50 & 25 & 13 & 69.04 \\
SJ-75 & 25 & 25 & 76.34 \\
SJ-160 & 25 & 93 & 96.08 \\
\hline
\end{tabular}

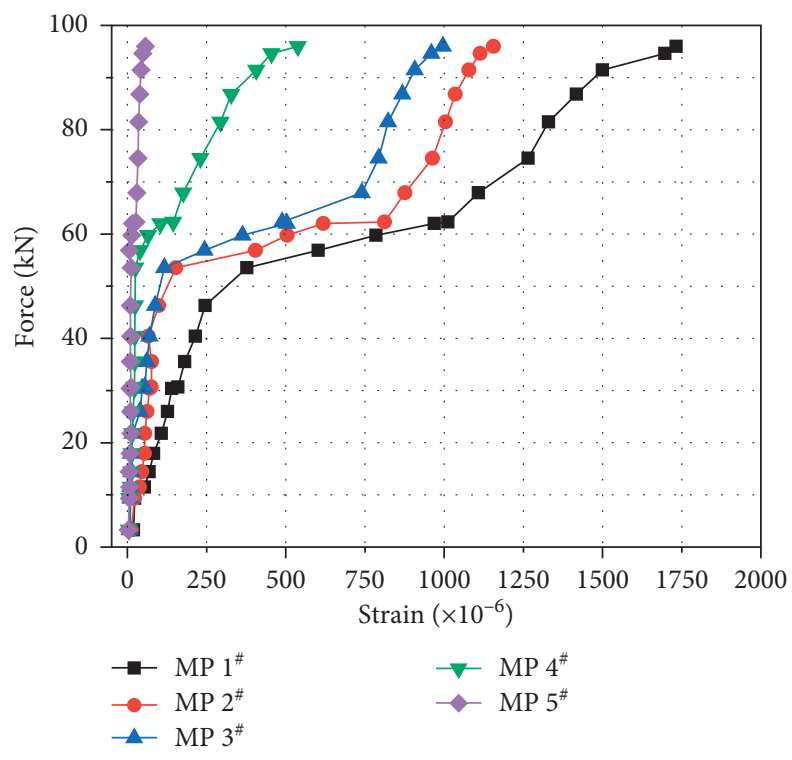

FIGURE 8: Curve of pulling force and strain.

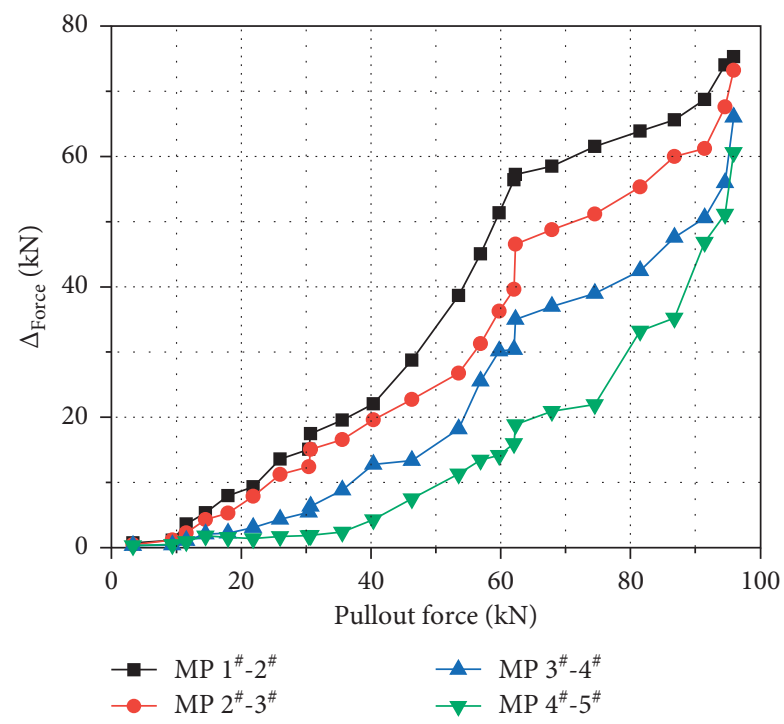

Figure 9: Curve of axial force difference between the two adjacent MPs with the pulling force.

concentrated in the anchoring agent, the influence range of the deformation is about $100 \mathrm{~mm}$ from the loading end, and the deformation field is tapered. When the pulling force is increased to $62 \mathrm{kN}$, the influence range of the deformation is about $150 \mathrm{~mm}$ from the loading end and the $\gamma$ in the concrete begins to increase, as shown in Figure 13(b). When the drawing force is increased to $75 \mathrm{kN}$, the deformation field of the anchoring agent affects about $200 \mathrm{~mm}$ from the loading end, as shown in Figure 13(c). In Figure 13(d), the drawing force is $96 \mathrm{kN}$, and the influence range of the 


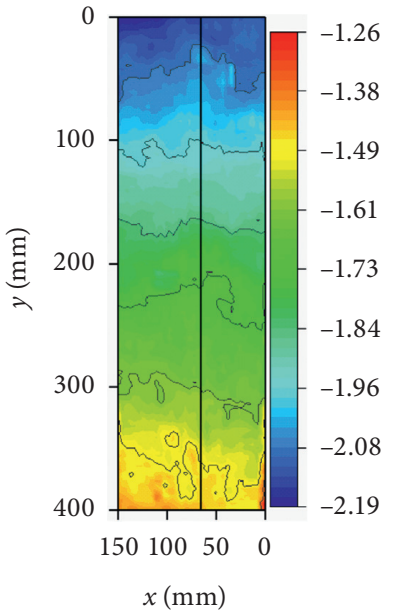

(a)

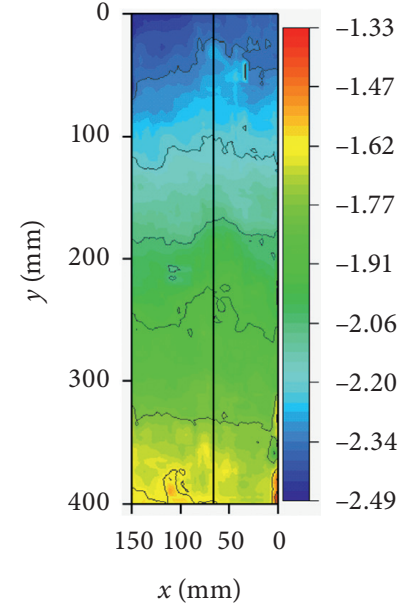

(b)

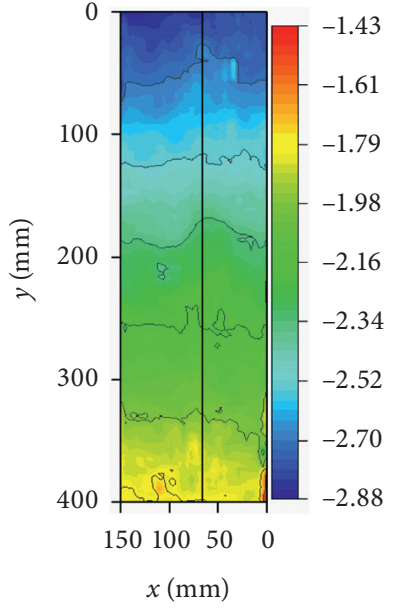

(c)

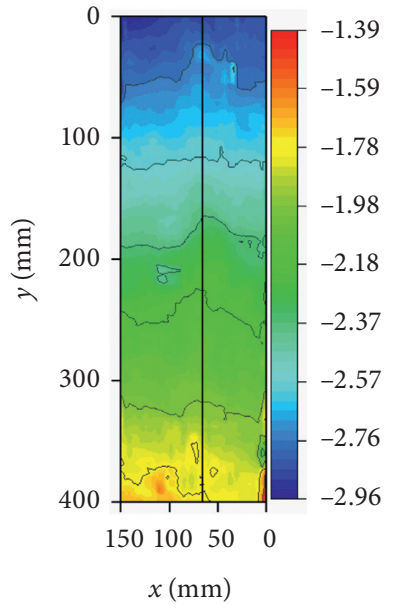

(d)

Figure 10: Horizontal displacement field of SJ-160. (a) $36 \mathrm{kN}$. (b) $62 \mathrm{kN}$. (c) $75 \mathrm{kN}$. (d) $96 \mathrm{kN}$.

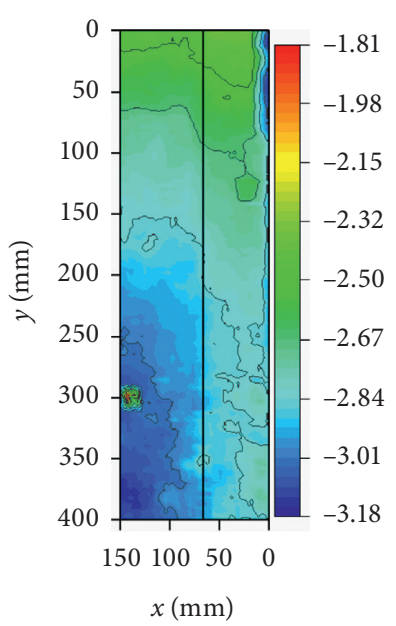

(a)

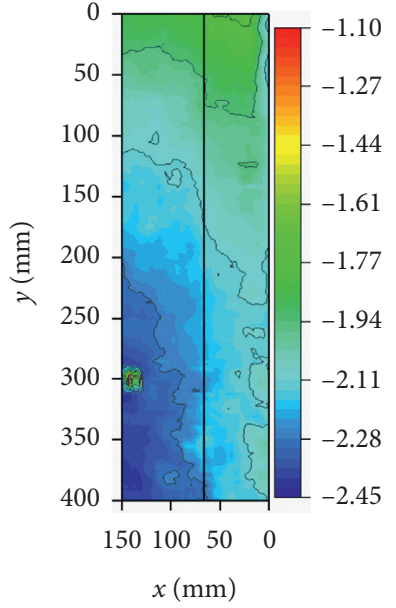

(b)

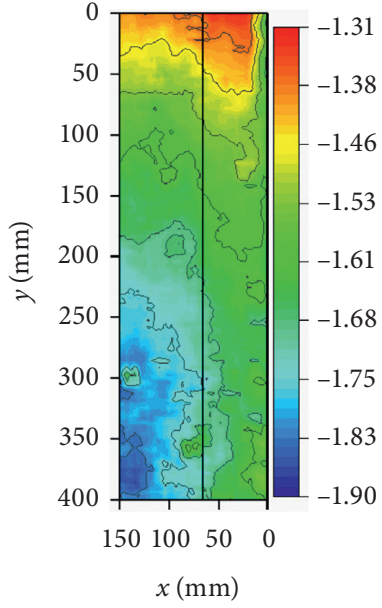

(c)

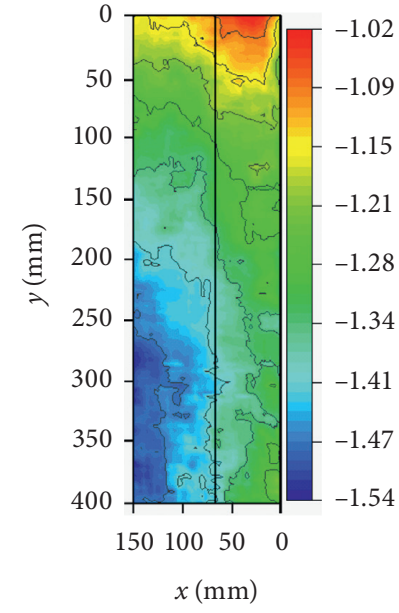

(d)

Figure 11: Vertical displacement field of SJ-160. (a) $36 \mathrm{kN}$. (b) $62 \mathrm{kN}$. (c) $75 \mathrm{kN}$. (d) $96 \mathrm{kN}$.

deformation field in the anchoring agent reaches $300 \mathrm{~mm}$ from the loading end.

From the above analysis, it can be found that (1) under the pulling force, the deformation of the anchoring agent expands from the loading end to the deep, and the deformation is continuously reduced and (2) due to the large thickness of the anchoring agent, during the entire loading stage, the maximum deformation value is always located at the interface between the bar and the anchoring agent.

4.3.3. Evolution Characteristics of the Displacement Field of the Anchor System. By analyzing the evolution characteristics of the relative displacement between the anchoring agent and the concrete, the transmission law of the force in the anchoring system is analyzed.

The relative displacement of the anchoring agent and the concrete is calculated as follows. The $5 \mathrm{~mm} \times 5 \mathrm{~mm}$ calculation window of the pixel point is selected in the anchoring agent and the concrete of the specimen, which center is $5 \mathrm{~mm}$ away from the interface, as shown in Figure 14 [33]. The displacement of the center point is represented by the average displacement of the speckle in the calculation window. The displacement difference between the center points of the two calculation windows in the $y$ direction represents the relative displacement of the anchoring agent and the concrete. The relative displacement of anchoring agent-concrete at 50,100, 150, 200, and $250 \mathrm{~mm}$ away from the loading end is analyzed, as shown in Figure 15.

From Figure 15, it can be found that in the initial stage of loading, the anchoring agent and the concrete are elastic as a whole, and the relative displacement increases slowly. As the drawing force increased to $62 \mathrm{kN}$, the anchoring agent and the concrete enter the plastic expansion stage. Slip occurs at the interface of the anchoring agent and the concrete. The 


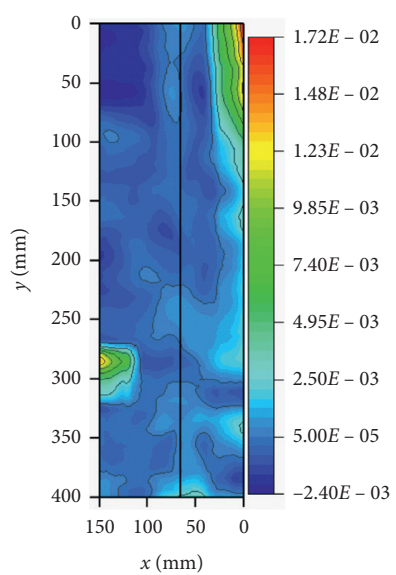

(a)

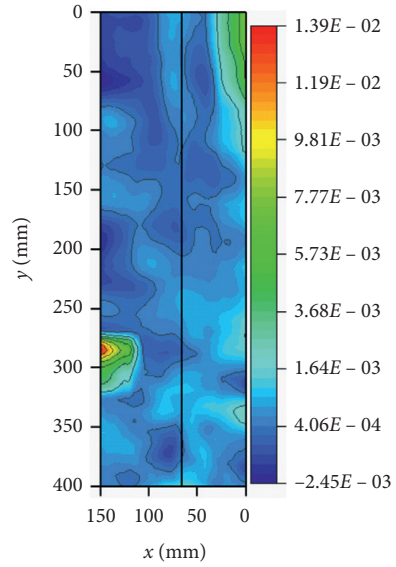

(b)

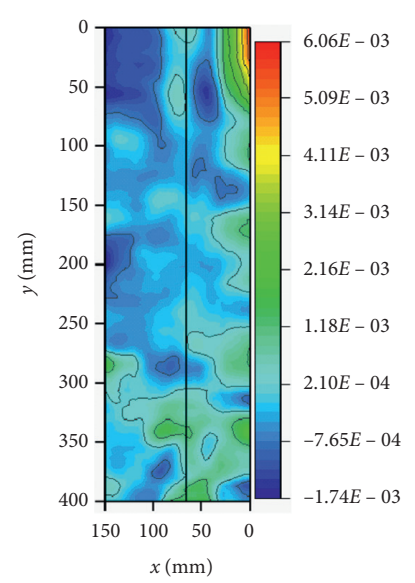

(c)

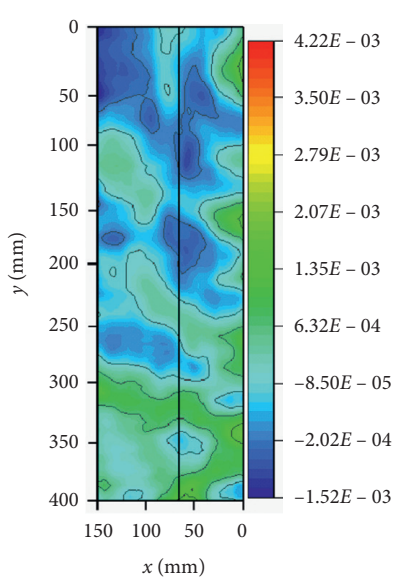

(d)

Figure 12: $\varepsilon_{1}$ field of SJ-160. (a) $36 \mathrm{kN}$. (b) $62 \mathrm{kN}$. (c) $75 \mathrm{kN}$. (d) $96 \mathrm{kN}$.

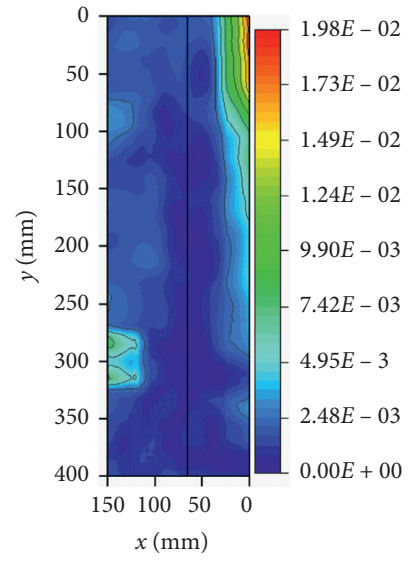

(a)

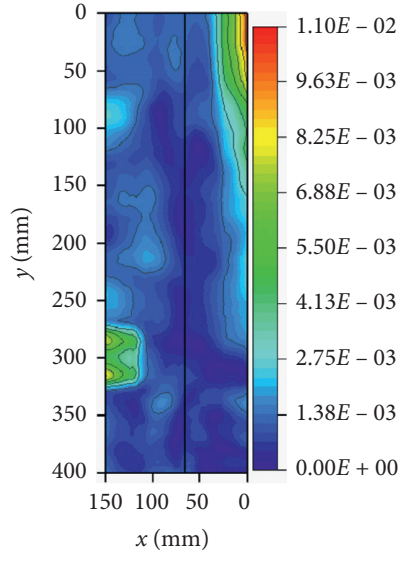

(b)

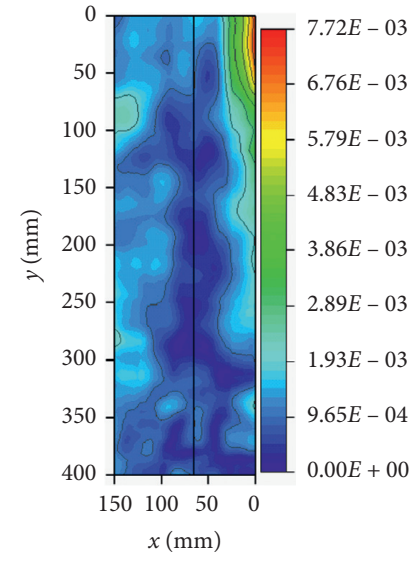

(c)

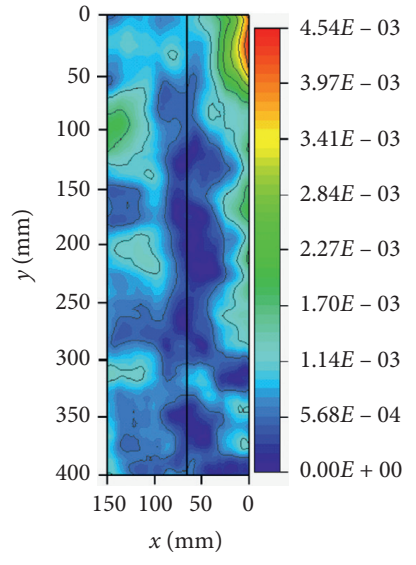

(d)

Figure 13: $\gamma$ field of SJ-160. (a) $36 \mathrm{kN}$. (b) $62 \mathrm{kN}$. (c) $75 \mathrm{kN}$. (d) $96 \mathrm{kN}$.

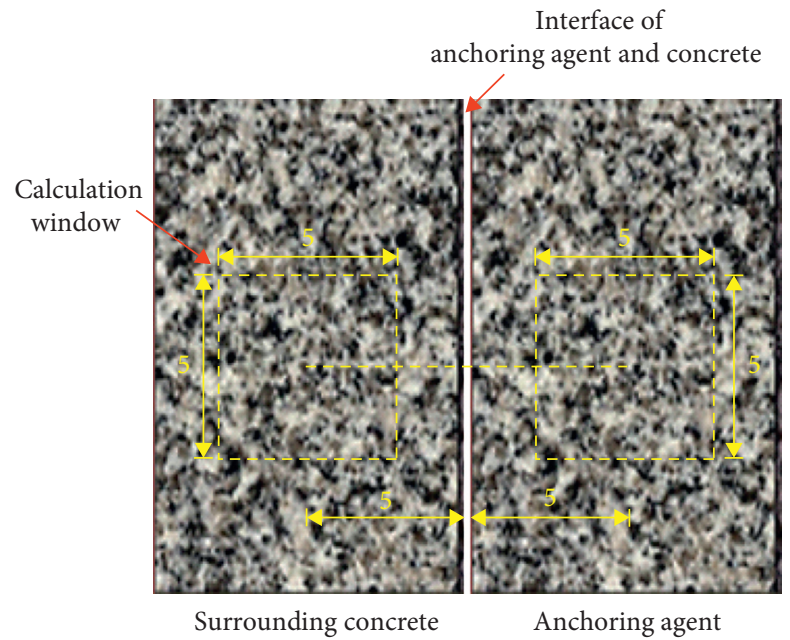

FIgURE 14: Calculation window of the displacement. 


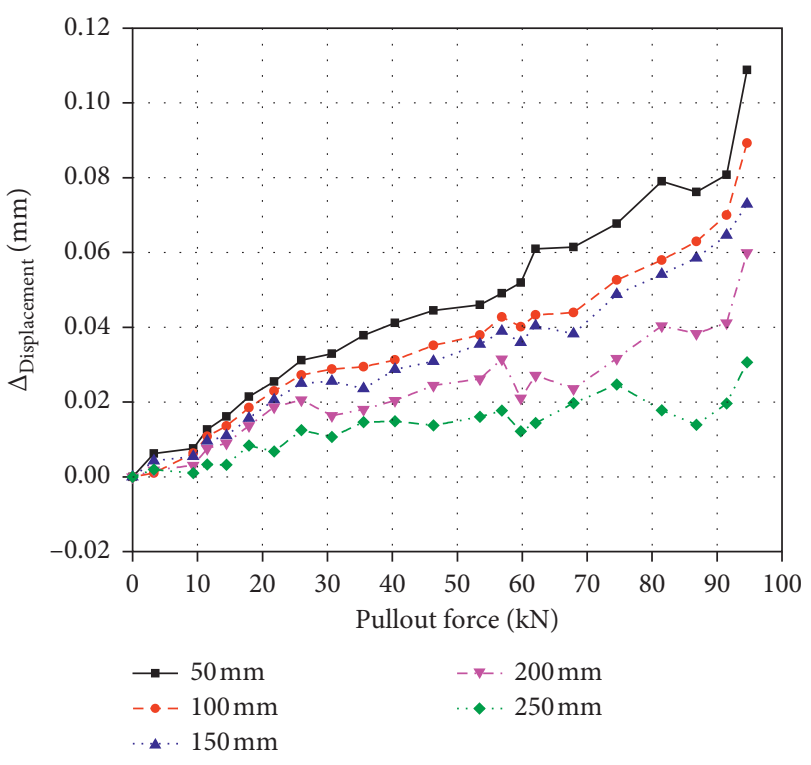

FIGURE 15: Evolution curve of the relative displacement.

increase of the relative displacement is significantly faster than the elastic stage. The relative displacement decreases with the increase of the distance from the loading end. At the same time, the interface between the bar and the anchoring agent is debonded in this stage, and the debonding region gradually expands from the loading end to the free end. When the pulling force exceeds $90 \mathrm{kN}$, most of the interface between the bar and the anchoring agent is debonded, and the deformation of the anchoring agent and the concrete rebounds. The relative displacement is affected by the residual friction between the anchoring agent and the concrete during the rebound process. From the above analysis, it can be found that the relative displacement decreases as the distance from the anchoring end increases, and the evolution rate of the relative displacement is related to the deformation stage of the anchoring agent and the concrete.

\section{Conclusion}

In the present work, a DIC-based method is proposed to analyze the anchorage system. The method is applied to measure the displacement field and the strain field of the anchorage system. The failure evolution law of the bonding interface in precast concrete structure is studied by the pullout test. The following can be concluded:

(1) The failure mode and ultimate bearing capacity of the anchor system is related with the thickness of the anchor agent.

(2) In the anchor system, the pulling force is gradually transferred from the loading end to the free end along the steel bar. And the greater the thickness of the anchoring agent, the deeper the transfer range.

(3) During the loading, the deformation of the anchoring system is mainly concentrated at the interface between the anchoring agent and the concrete and expands to the depth along the steel bar.
(4) The failure evolution rate of the anchorage system is related to the loading stage. The failure evolution of the anchor system can be divided into the elastic phase, the plastic phase, and the deformation rebound phase.

\section{Data Availability}

The experimental data used to support the findings of this study are included within the article.

\section{Conflicts of Interest}

The authors declare that there are no conflicts of interest regarding the publication of this paper.

\section{Acknowledgments}

This work was financially supported by the National Natural Science Foundation of China (grant nos. 51408009 and 51608010), Fundamental Research Funds for the Beijing's Universities (110052971921/062), and Yuyou Talent Project of North China University of Technology (grant no. XN012/ 044) for this study.

\section{References}

[1] M. P. Culmo, Accelerated Bridge Construction: Experience in Design, Fabrication and Erection of Prefabricated Bridge Elements and Systems: Final Manual. No. FHWA-HIF-12-013. United States, Federal Highway Administration, Office of Bridge Technology, Washington, DC, USA, 2011.

[2] D. J. Raynor, D. E. Lehman, and J. F. Stanton, "Bond-slip response of reinforcing bars grouted in ducts," Aci Structural Journal, vol. 99, no. 5, pp. 568-576, 2002.

[3] N. Tullini and F. Minghini, "Cyclic test on a precast reinforced concrete column-to-foundation grouted duct connection," Bulletin of Earthquake Engineering, vol. 18, no. 4, pp. 16571691, 2020.

[4] J.-J. Fan, D.-C. Feng, G. Wu, S. Hou, and Y. Lu, "Experimental study of prefabricated RC column-foundation assemblies with two different connection methods and using large-diameter reinforcing bars," Engineering Structures, vol. 205, p. 110075, 2020.

[5] P. N. Faye, Y. Ye, and B. Diao, "Bond effects between concrete and steel bar using different diameter bars and different initial crack width," Advances in Civil Engineering, vol. 2017, Article ID 8205081, 11 pages, 2017.

[6] H. Ma and Z. Zhang, "Paving an engineered cementitious composite (ECC) overlay on concrete airfield pavement for reflective cracking resistance," Construction and Building Materials, vol. 252, p. 119048, 2020.

[7] J. Silfwerbrand, "Shear bond strength in repaired concrete structures," Materials and Structures, vol. 36, no. 6, pp. 419-424, 2003.

[8] M. S. Ashtiani, R. P. Dhakal, and A. N. Scott, "Post-yield bond behaviour of deformed bars in high-strength self-compacting concrete," Construction \& Building Materials, vol. 44, no. 8, pp. 236-248, 2013.

[9] Z. Zhang, Q. Zhang, and V. C. Li, "Multiple-scale investigations on self-healing induced mechanical property recovery of ECC," Cement and Concrete Composites, vol. 103, pp. 293-302, 2019. 
[10] M. Harajli, B. Hamad, and K. Karam, "Bond-slip response of reinforcing bars embedded in plain and fiber concrete," Journal of Materials in Civil Engineering, vol. 14, no. 6, pp. 503-511, 2002.

[11] S. P. Singer, Field Verification of Load Transfer Mechanics of Fully Grouted Roof Bolts, US Bureau of Mines, (9301), Washington, DC, USA, 1990.

[12] N. I. Aziz and B. Webb, "Study of load transfer capacity of bolts using short encapsulation push test," in Proceedings of 4th Underground Coal Operators Conference, pp. 72-80, Wollongong, Australia, February 2003.

[13] S. Yazici and P. K. Kaiser, "Bond strength of grouted cable bolts," International Journal of Rock Mechanics and Mining Sciences \& Geomechanics Abstracts, vol. 29, no. 3, pp. 279292, 1992.

[14] A. S Ezeldin and P. N. Balaguru, "Characterization of bond between fiber concrete and reinforcing bars using nonlinear finite element analysis," Computers \& Structures, vol. 37, no. 4, pp. 569-584, 1990.

[15] W. Yeih, R. Huang, J. Chang, and C. Yang, "Pullout test for determining interface properties between rebar and concrete," Advanced Cement Based Materials, vol. 5, no. 2, pp. 57-65, 1997.

[16] Z. Zhang, F. Yang, J.-C. Liu, and S. Wang, "Eco-friendly high strength, high ductility engineered cementitious composites (ECC) with substitution of fly ash by rice husk ash," Cement and Concrete Research, vol. 137, p. 106200, 2020.

[17] Z. Zhang, F. Qin, H. Ma, and L. Xu, "Tailoring an impact resistant engineered cementitious composite (ECC) by incorporation of crumb rubber," Construction and Building Materials, vol. 262, p. 120116, 2020.

[18] B. A. Tayeh, B. H. Abu Bakar, and M. A. Megat Johari, "Characterization of the interfacial bond between old concrete substrate and ultra high performance fiber concrete repair composite," Materials and Structures, vol. 46, no. 5, pp. 743-753, 2012.

[19] W. H. Peters and W. F. Ranson, "Digital imaging techniques in experimental stress analysis," Optical Engineering, vol. 21, no. 3, pp. 427-431, 1982.

[20] M. Sutton, W. Wolters, W. Peters, W. Ranson, and S. McNeill, "Determination of displacements using an improved digital correlation method," Image and Vision Computing, vol. 1, no. 3, pp. 133-139, 1983.

[21] I. Yamaguchi, "A laser-speckle strain-gauge," Journal of Physics, vol. 14, no. 4, pp. 1270-1273, 1981.

[22] S. Zhang and Y. Liu, "Damage detection of bridges monitored within one cluster based on the residual between the $\mathrm{cu}$ mulative distribution functions of strain monitoring data," Structural Health Monitoring, vol. 19, no. 6, pp. 1764-1789, 2020.

[23] M. Muller, E. Toussaint, J.-F. Destrebecq, and M. Grédiac, "Experimental and numerical study of reinforced concrete specimens strengthened with composite plates," Composites Part A: Applied Science and Manufacturing, vol. 35, no. 7-8, pp. 885-893, 2004.

[24] S.-H. Tung, M.-H. Shih, and W.-P. Sung, "Development of digital image correlation method to analyse crack variations of masonry wall," Sadhana, vol. 33, no. 6, pp. 767-779, 2008.

[25] B. Ghiassi, J. Xavier, D. V. Oliveira, and P. B. Lourenço, "Application of digital image correlation in investigating the bond between FRP and masonry," Composite Structures, vol. 106, pp. 340-349, 2013.
[26] J. D. Helm, "Digital image correlation for specimens with multiple growing cracks," Experimental Mechanics, vol. 48, no. 6, pp. 753-762, 2008.

[27] S. Choi and S. P. Shah, "Measurement of deformations on concrete subjected to compression using image correlation," Experimental Mechanics, vol. 37, no. 3, pp. 307-313, 1997.

[28] G. Ruocci, C. Rospars, G. Moreau et al., "Digital image correlation and noise-filtering approach for the cracking assessment of massive reinforced concrete structures," Strain, vol. 52, no. 6, pp. 503-521, 2016.

[29] X. F. Yao, L. B. Meng, J. C. Jin, and H. Y. Yeh, "Full-field deformation measurement of fiber composite pressure vessel using digital speckle correlation method," Polymer Testing, vol. 24, no. 2, pp. 245-251, 2005.

[30] Z. Wang, Z. Ma, Y. Zhou, and C. Lu, "Measurement of the mechanical properties of nickel film based on the full-field deformation: an improved blister method," Progress in Natural Science: Materials International, vol. 23, no. 5, pp. 453458, 2013.

[31] L. B. Meng, S. P. Ma, and G. C. Jin, "Comparison of subpixel displacement measurement methods for digital speckle correlation measurement," Experimental Mechanics, vol. 3, pp. 343-348, 2003.

[32] China Construction Industry Press, "Code for design of concrete structures," China Construction Industry Press, Beijing, China, GB50010-2010, 2015.

[33] Y. M. Song, S. P. Ma, X. B. Yang, and X. Wang, "Experimental investigation on failure of rock by digital speckle correlation methods," Chinese Journal of Rock Mechanics and Engineering, vol. 30, no. 1, pp. 170-175, 2011. 